\title{
The clinical usefulness of natural killer cell activity in patients with suspected or diagnosed prostate cancer: an observational cross-sectional study
}

This article was published in the following Dove Press journal:

OncoTargets and Therapy

\author{
Wan Song' \\ ji Woong Yu ${ }^{2}$ \\ Byong Chang Jeong ${ }^{2}$ \\ Seong II Seo ${ }^{2}$ \\ Seong Soo Jeon ${ }^{2}$ \\ Hyun Moo Lee ${ }^{2}$ \\ Han Yong Choi ${ }^{3}$ \\ Eun-Suk Kang ${ }^{4}$ \\ Hwang Gyun Jeon ${ }^{2}$ \\ 'Department of Urology, Ewha \\ Womans University School of \\ Medicine, Seoul, Korea; ${ }^{2}$ Department \\ of Urology, Samsung Medical Center, \\ Sungkyunkwan University School of \\ Medicine, Seoul, Korea; ${ }^{3}$ Department \\ of Urology, Kangbuk Samsung \\ Hospital, Sungkyunkwan University \\ School of Medicine, Seoul, Korea; \\ ${ }^{4}$ Department of Laboratory Medicine \\ and Genetics, Samsung Medical \\ Center, Sungkyunkwan University \\ School of Medicine, Seoul, Korea
}

Correspondence: Hwang Gyun Jeon Department of Urology, Samsung Medical Center, Sungkyunkwan University School of Medicine, 8I Irwon-ro, Gangnam-gu, Seoul, 135-7I0, Korea

Email hwanggyun.jeon@samsung.com
Purpose: To investigate the clinical usefulness of natural killer cell activity (NKA) for detection of prostate cancer ( $\mathrm{PCa}$ ) and prediction of Gleason grade.

Patients and methods: We prospectively enrolled 221 patients who underwent transrectal ultrasound-guided prostate biopsy for suspected $\mathrm{PCa}$ due to elevated prostate-specific antigen (PSA) $>2.5 \mathrm{ng} / \mathrm{mL}$ or abnormal findings on digital rectal examination $(\mathrm{n}=146)$, or who were diagnosed with PCa ( $n=75)$ between 2016 and 2017. The NKA was compared according to PCa and Gleason grade. Correlation analysis was used to evaluate associations among NKA, PCa, and Gleason grade, and expressed using distribution dot plots. The absolute risk and relative risk of $\mathrm{PCa}$, and odds ratios at different cut-off values of NKA were calculated.

Results: Of the total 221 patients, PCa was identified in 135 (61.9\%) patients. When patients were divided according to PCa, there was no significant difference in NKA $(1,267.6$ vs $1,198.9 \mathrm{pg} / \mathrm{mL}, P=0.491)$. Furthermore, in 135 patients with $\mathrm{PCa}$, the NKA was not significantly different according to Gleason grade $(P=0.893)$. These results were not changed when confined to the patients with PSA between 2.5 and $10.0 \mathrm{ng} / \mathrm{mL}$ ( $P=0.654$ and $P=0.672$, respectively). In addition, there was no significant difference in the risk of $\mathrm{PCa}$ at different cut-off values of NKA.

Conclusion: These results indicate that NKA does not appear to be very useful for detection of PCa and prediction of Gleason grade. Further large multi-institutional studies are required to verify the role of NKA in PCa detection and Gleason grade prediction.

Keywords: immunosurveillance, natural killer cell activity, prostate cancer, Gleason score

\section{Introduction}

Along with widespread use of prostate-specific antigen (PSA) for screening and early detection of prostate cancer (PCa) ${ }^{1-3}$ the diagnosis of PCa has abruptly shifted with concurrent improvement of transrectal ultrasound (TRUS)-guided prostate biopsy., However, PSA is an imperfect serum marker; the American Cancer Society reports a sensitivity of only $21 \%$ for any PCa, while specificity is $91 \%$ when the normal PSA level is defined as less than $4.0 \mathrm{ng} / \mathrm{mL} .^{6}$ Therefore, approximately $80 \%$ of patients will receive an unnecessary biopsy, and some patients will suffer over-diagnosis and the associated over-treatment. ${ }^{7-9}$ In addition, TRUS-guided prostate biopsy is an invasive procedure that can cause hematuria, hematochezia, urinary tract infection, and bacteremia. ${ }^{10-12}$ Consequently, a more reliable biomarker is needed to supplement PSA for the diagnosis of PCa.

To date, natural killer (NK) cells have gained increasing attention in the cancer setting, as they are involved in innate immunity and serve a major role in anticancer 
mechanisms. ${ }^{13,14} \mathrm{NK}$ cells show potent natural cytotoxicity to eliminate cancer cells directly and also play a role in the adaptive immune system by secreting cytokines that suppress tumor progression. ${ }^{15-17}$ The relationship between natural killer cell activity (NKA) and cancer has been studied for many decades, and reduction of NKA is associated with advanced stage $\mathrm{PCa}$, progression of $\mathrm{PCa}$, and the presence of circulating tumor cells. ${ }^{18-20}$ However, application of NKA as a marker for the detection and risk assessment of PCa has not been fully investigated.

To address these issues, we measured NKA in patients who were diagnosed with PCa or who underwent TRUSguided prostate biopsy for suspected PCa. The aim of this study is to analyze the clinical usefulness of NKA for the diagnosis of $\mathrm{PCa}$ in patients with suspected $\mathrm{PCa}$, and to examine whether NKA correlated with the Gleason grade of PCa.

\section{Patients and methods Patients and data collection}

This observational cross-sectional study was approved by the Institutional Review Board of Samsung Medical Center, and written informed consent was obtained from each study participant. We enrolled 223 patients who underwent TRUSguided prostate biopsy for suspected $\mathrm{PCa}$ due to elevated PSA $>2.5 \mathrm{ng} / \mathrm{mL}$ and/or abnormal findings on digital rectal examination $(n=147)$, or who were diagnosed with PCa $(n=76)$ between November 2016 and July 2017.

Eligible criteria for enrollment were as follows: 1) male aged 40 to 75 years, 2) no history of diagnosis or treatment for other malignancies, 3) no history of neoadjuvant androgen deprivation therapy for $\mathrm{PCa}$, and 4) no history of inflammatory conditions that might affect the immune system. From these patients, we excluded two who had incomplete data for Gleason grade. Ultimately, 221 patients were analyzed in our study.

\section{Data collection}

The clinical characteristics of the patients including age, PSA, and NKA were recorded. For patients diagnosed with $\mathrm{PCa}$, Gleason grade was recorded using the new grading system proposed in the 2014 consensus of International Society of Urological Pathology. ${ }^{21}$ We divided the patients into two groups according to the presence of PCa, and NKA was compared between the two groups and according to Gleason grade. The absolute risk and relative risk of $\mathrm{PCa}$ and odds ratios at different cut-off values of NKA were calculated.

\section{Measurement of NKA}

Cytotoxic activity of NK cells was measured using the NK Vue $^{\circledR}$ Kit (ATgen, Sungnam, Korea). One milliliter of whole blood was collected using NK Vue Tubes and placed into the incubator at $37^{\circ} \mathrm{C}$ for 24 hours under $5 \% \mathrm{CO}_{2}$ with the indicated dose of Promoca ${ }^{\mathrm{TM}}$ (ATGen, Seongnam-si, Korea) and $1 \mathrm{~mL}$ of RPMI 1640 medium (Cellgro/Mediatech, Manassas, VA, USA). After that, the supernatant was collected and centrifuged at $11,500 \times g$ for 5 minutes. The supernatant was collected in another conical $1.5 \mathrm{~mL}$ Eppendorf tube and immediately loaded onto the enzyme-linked immunosorbent assay (ELISA) plates.

During the 24 hours' incubation at $37^{\circ} \mathrm{C}$, stimulatory cytokine (Promoca) stimulated the NKA and IFN-g secreted into the plasma was quantitated with an ELISA. IFN-g was measured in $\mathrm{pg} / \mathrm{mL}$ and the dynamic range of the ELISA was from 40 to $2,000 \mathrm{pg} / \mathrm{mL}$. When the measured level of IFN-g was below or above the dynamic range, it was recorded as a value of $40 \mathrm{pg} / \mathrm{mL}$ or $2,000 \mathrm{pg} / \mathrm{mL}$, respectively.

\section{Statistical analysis}

Quantitative variables were expressed as median (range) or mean (SD) and qualitative variables as absolute values (percentage). An independent $t$-test was used to compare age, PSA, and NKA. Correlation analysis was used to evaluate associations among NKA, PCa, and Gleason grade, and expressed using distribution dot plots. NKA according to Gleason grade was compared using one-way analysis of variance. All statistical analyses were performed using IBM SPSS statistics for Window, version 23.0 (IBM Corporation, Armonk, NY, USA) and MedCalc version 13.0 (MedCalc Software, Mariakerke, Belgium). Two-tailed $P$-values $<0.05$ were considered statistically significant.

\section{Results}

The baseline characteristics of all 221 patients with suspected or diagnosed PCa are summarized in Table 1. Among the total 221 patients, the median age was 66.0 years. Median PSA and NKA were $5.78 \mathrm{ng} / \mathrm{mL}$ and $1,337.8 \mathrm{pg} / \mathrm{mL}$, respectively. Gleason grade confirmed by TRUS-guided biopsy was as follows: Gleason grade 6 for 43 (31.9\%) patients, Gleason grade $7(3+4)$ for 34 (25.1\%) patients, Gleason grade $7(4+3)$ for 15 (11.1\%) patients, Gleason grade 8 for 25 (18.6\%) patients, and Gleason grade 9-10 for 18 (13.3\%) patients. When patients were divided into two groups according to the presence of $\mathrm{PCa}$, a significant difference was identified in age $(P=0.001)$ but not in PSA $(P=0.066)$ or NKA $(P=0.491$, Figure 1$)$. In addition, when we restricted the analysis to patients with PSA between 
Table I Baseline characteristics

\begin{tabular}{|c|c|c|c|c|}
\hline \multirow[t]{2}{*}{ Parameters } & \multicolumn{3}{|c|}{ Prostate cancer } & \multirow[t]{2}{*}{$P$-value } \\
\hline & Total N (\%) & Detected & Not detected & \\
\hline \multicolumn{5}{|l|}{ Overall patients } \\
\hline $\mathrm{N}$ & $221(100.0)$ & $135(61.9)$ & $86(38.9)$ & \\
\hline Age, years & & & & 0.001 \\
\hline Median (range) & $66.0(39.0-81.0)$ & $67.0(50.0-81.0)$ & $64.0(39.0-80.8)$ & \\
\hline Mean (SD) & $65.5(7.6)$ & $66.9(7.1)$ & $63.3(7.9)$ & \\
\hline PSA, ng/mL & & & & 0.066 \\
\hline Median (range) & $5.78(0.79-1,727.10)$ & $6.61(0.79-1,727.10)$ & $4.77(0.80-37.34)$ & \\
\hline Mean (SD) & $22.04(128.96)$ & $32.25(164.37)$ & $6.02(4.77)$ & \\
\hline $\mathrm{NKA}, \mathrm{pg} / \mathrm{mL}$ & & & & 0.491 \\
\hline Median (range) & I,337.8 (40.0-2,000.0) & I,373.0 (40.0-2,000.0) & I, I39.I (40.0-2,000.0) & \\
\hline Mean (SD) & I,240.9 (72।.7) & I,267.6 (742.8) & I, $198.9(687.6)$ & \\
\hline \multicolumn{5}{|c|}{ Biopsy Gleason grade } \\
\hline 6 & & $43(31.9)$ & & \\
\hline $7(3+4)$ & & $34(25.1)$ & & \\
\hline $7(4+3)$ & & $15(1 \mathrm{I} .1)$ & & \\
\hline 8 & & $25(18.6)$ & & \\
\hline $9-10$ & & $18(13.3)$ & & \\
\hline \multicolumn{5}{|c|}{ Patients with PSA between } \\
\hline \multicolumn{5}{|l|}{2.5 and $10.0 \mathrm{ng} / \mathrm{mL}$} \\
\hline $\mathrm{N}$ & $159(100.0)$ & $89(56.0)$ & $70(44.0)$ & \\
\hline Age, years & & & & 0.019 \\
\hline Median (range) & $65.0(47.0-80.8)$ & $66.0(50.0-79.0)$ & $64.0(47.0-80.8)$ & \\
\hline Mean (SD) & $64.9(7.2)$ & $66.1(6.9)$ & $63.4(7.4)$ & \\
\hline PSA, ng/mL & & & & 0.031 \\
\hline Median (range) & $5.09(2.53-9.93)$ & $5.53(2.53-9.93)$ & $4.67(2.61-9.06)$ & \\
\hline Mean (SD) & $5.38(1.72)$ & $5.64(1.7 I)$ & $5.05(1.70)$ & \\
\hline $\mathrm{NKA}, \mathrm{pg} / \mathrm{mL}$ & & & & 0.654 \\
\hline Median (range) & I,342.I (40.0-2,000.0) & I,375.I (40.0-2,000.0) & $1,143.9(40.0-2,000.0)$ & \\
\hline Mean (SD) & I,24I.8 (736.8) & I,265.I (762.7) & $\mathrm{I}, 2 \mathrm{I} 2.2(706.8)$ & \\
\hline \multicolumn{5}{|c|}{ Biopsy Gleason grade } \\
\hline 6 & & $38(42.7)$ & & \\
\hline $7(3+4)$ & & $34(38.2)$ & & \\
\hline $7(4+3)$ & & 0 & & \\
\hline 8 & & $10(11.2)$ & & \\
\hline $9-10$ & & $7(7.9)$ & & \\
\hline
\end{tabular}

Abbreviations: NKA, natural killer cell activity; PSA, prostate-specific antigen.

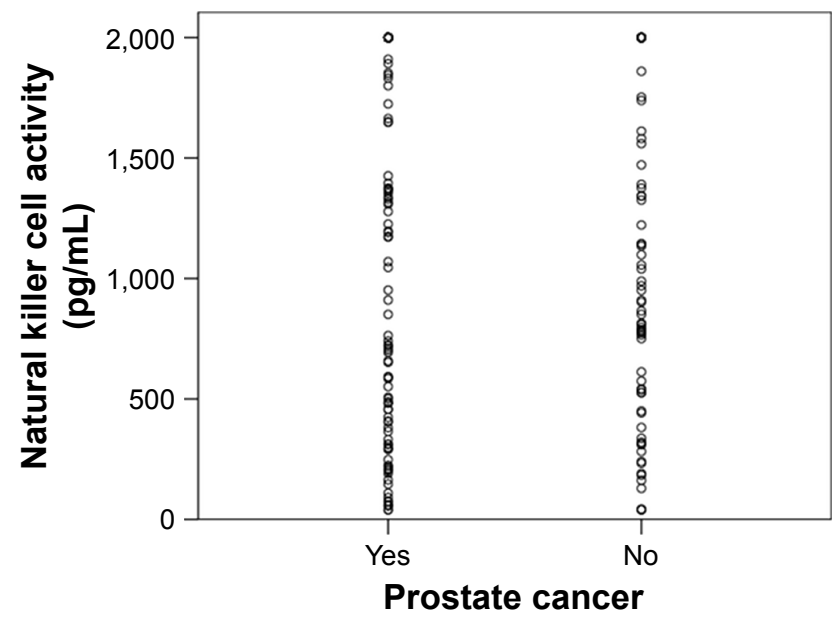

Figure I Distribution dot plot comparing natural killer cell activity between patients with and without prostate cancer.
2.5 and $10.0 \mathrm{ng} / \mathrm{mL}$, patients with $\mathrm{PCa}$ were older $(P=0.019)$ and had higher PSA $(P=0.031)$ than patients without. However, NKA was not significantly different $(P=0.654)$.

NKA according to Gleason grade is presented in Table 2. Median NKA was as follows: $1,394.9 \mathrm{pg} / \mathrm{mL}$ for Gleason grade 6, 1,519.5 pg/mL for Gleason grade $7(3+4)$, $2,000.0 \mathrm{pg} / \mathrm{mL}$ for Gleason grade 7 (4+3), $1,329.1 \mathrm{pg} / \mathrm{mL}$ for Gleason grade 8, and 1,505.7 pg/mL for Gleason grade 9-10. There was no significant difference in NKA values among Gleason grade groups $(P=0.893$, Figure 2$)$. The results in patients with PSA between 2.5 and $10.0 \mathrm{ng} / \mathrm{mL}$ were also not significantly different based on Gleason grade $(P=0.672)$.

The risk of PCa at different cut-off values of NKA is detailed in Table 3. Among all 221 patients, when the NKA 
Table 2 NKA according to Gleason grade

\begin{tabular}{|c|c|c|c|c|c|c|}
\hline \multirow[t]{2}{*}{ NKA } & \multicolumn{5}{|l|}{ Gleason grade } & \multirow[t]{2}{*}{$P$-value } \\
\hline & 6 & $7(3+4)$ & $7(4+3)$ & 8 & $9-10$ & \\
\hline Overall patients & & & & & & 0.893 \\
\hline Median (range) & $1,394.9(56.3-2,000.0)$ & I,5 I $9.5(72.7-2,000.0)$ & $2,000.0(57.4-2,000.0)$ & I,329.I (40.0-2,000.0) & I,505.7 (I $46.3-2,000.0)$ & \\
\hline Mean (SD) & $\mathrm{I}, 349.6(697.2)$ & I,246.3 (786.8) & I,3। I.3 (860.2) & I, I 73.3 (720.9) & $\mathrm{I}, 206.5(752.7)$ & \\
\hline $\begin{array}{l}\text { Patients with PSA } \\
\text { between }\end{array}$ & & & & & & 0.672 \\
\hline \multicolumn{7}{|l|}{2.5 and $10.0 \mathrm{ng} / \mathrm{mL}$} \\
\hline Median (range) & I,747.2 (56.3-2,000.0) & I,375.I (75.6-2,000.0) & $720.7(57.4-2,000.0)$ & I,277.5 (40.0-2,000.0) & I,724.6 (3। I. .3-2,000.0) & \\
\hline Mean (SD) & I,375.8 (7I3.9) & I,246.5 (783.4) & 977.1 (924.2) & I,082.0 (809.2) & $\mathrm{I}, 285.9(8 \mathrm{I} 2.6)$ & \\
\hline
\end{tabular}

Abbreviations: NKA, natural killer cell activity; PSA, prostate-specific antigen.

value was less than $200 \mathrm{pg} / \mathrm{mL}$, the absolute risk of PCa was $63.2 \%(12 / 19)$. The absolute risk of $\mathrm{PCa}$ in patients with an NKA value more than $200 \mathrm{pg} / \mathrm{mL}$ was $60.9 \%$ (123/202). The corresponding relative risk $(95 \% \mathrm{CI})$ and odds ratio $(95 \%$ CI) were $1.04(0.72-1.49)$ and $1.10(0.42-2.91)$, respectively, demonstrating that there was no significant difference in the risk of PCa based on an NKA cut-off of $200 \mathrm{pg} / \mathrm{mL}$. The risk of PCa in patients with PSA between 2.5 and $10.0 \mathrm{ng} / \mathrm{mL}$ at different cut-off values of NKA is summarized in Table 3.

\section{Discussion}

Among the 221 total patients enrolled in the present study, PCa was identified in 135 (61.9\%). When patients were divided into two groups according to the presence of $\mathrm{PCa}$, there was no significant difference in the value of NKA $(P=0.491)$. In addition, for the 135 patients with $\mathrm{PCa}$, the value of NKA was not significantly different according to Gleason grade $(P=0.893)$. These results did not change when restricted to patients with PSA between 2.5 and $10.0 \mathrm{ng} / \mathrm{mL}$ ( $P=0.654$ and $P=0.672$, respectively). Our results suggest that the value of NKA is not very useful for detection of $\mathrm{PCa}$ and

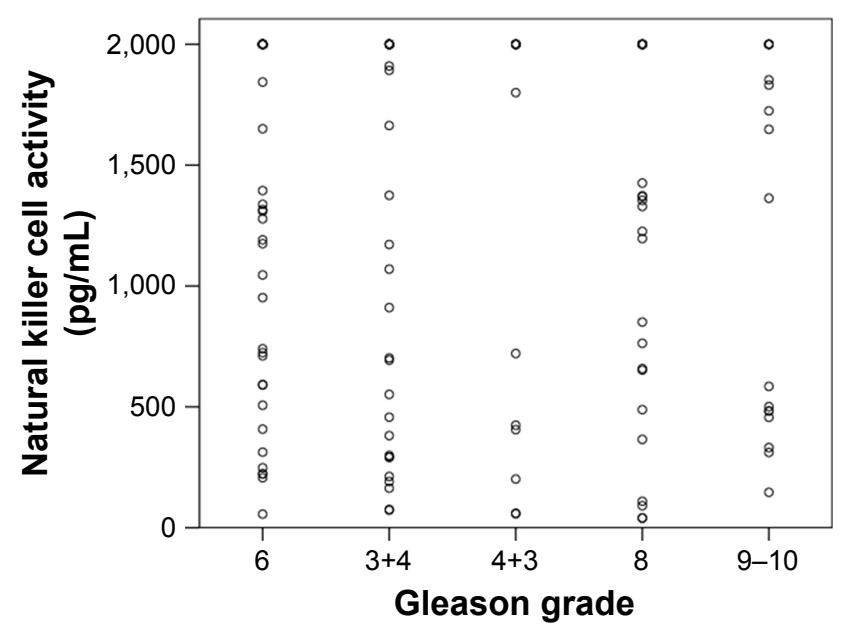

Figure 2 Distribution dot plot comparing natural killer cell activity in patients with prostate cancer according to Gleason grade. prediction of Gleason grade. To the best of our knowledge, this is the first and largest study to evaluate correlations among NKA, PCa detection, and Gleason grade.

Recently, immunotherapy has been developed that can counteract cancer-mediated immunosuppression for solid tumors, such as PCa, with a focus on alternative therapeutic options for metastatic cancer. In particular, NK cells play an important role in tumor immuno-surveillance because they activate both the innate and adaptive immune responses in reaction to tumor cells, even without surface antigens. ${ }^{22,23} \mathrm{NK}$ cells exert their natural cytotoxicity to remove malignant cells without pre-sensitization. ${ }^{15}$ In addition, they prompt the adaptive immune response to cope with the escape mechanism of tumor cells by secreting pro-inflammatory cytokines. ${ }^{16}$ NKA is regulated by various activating and inhibitory receptors on the cell surface, thereby initiating cytolytic processes in tumor cells and avoiding tissue damage. ${ }^{13}$ Consequently, the role of NK cells in metastatic PCa has previously been explored in several studies..$^{24,25}$

Lin et $\mathrm{al}^{25}$ evaluated the role of NK cells in vitro in castration-resistant $\mathrm{PCa}$ (CRPC) cell lines (CWR22Rv1 and VCaP, both enzalutamide-resistant) and found that CRPC cells collected NK cells more readily than normal prostate cells. These recruited NK cells decreased enzalutamideresistant CRPC cell growth and invasion by suppressing ARv7 expression. In response, however, CRPC cells avoided the anticancer activity of NK cells through an immunosuppressive reaction of secreting an NKG2D ligand-expressing PCa-derived exosome. ${ }^{26}$

Furthermore, Pasero et $\mathrm{al}^{24}$ isolated NK cells from the peripheral blood of 39 patients with metastatic $\mathrm{PCa}$ and evaluated their relationship with overall survival (OS, time from diagnosis of metastases to death or last follow-up) and time to castration resistance (TCR, time from castration to castration resistance). They found that high activity of NK cells was significantly associated with longer OS, and longer TCR, of more than 18 months. In addition, NKp30 and 
Table 3 Risk of prostate cancer according to NKA

\begin{tabular}{|c|c|c|c|c|c|c|}
\hline \multirow[t]{2}{*}{ NKA (pg/mL) } & \multirow{2}{*}{$\begin{array}{l}\text { Total, } \\
\text { N (\%) }\end{array}$} & \multicolumn{2}{|c|}{ Prostate cancer, N (\%) } & \multirow{2}{*}{$\begin{array}{l}\text { Absolute } \\
\text { risk (\%) }\end{array}$} & \multirow{2}{*}{$\begin{array}{l}\text { Relative risk } \\
(95 \% \mathrm{Cl})\end{array}$} & \multirow{2}{*}{$\begin{array}{l}\text { Odds ratio } \\
(95 \% \mathrm{Cl})\end{array}$} \\
\hline & & Detected & Not detected & & & \\
\hline \multicolumn{7}{|l|}{ Overall patients } \\
\hline$<200$ & $19(8.6)$ & $12(63.2)$ & $7(36.8)$ & 63.2 & $1.04(0.72-1.49)$ & $1.10(0.42-2.91)$ \\
\hline$<300$ & $31(14.0)$ & $21(67.7)$ & $10(32.3)$ & 67.7 & I.I $3(0.86-1.48)$ & $1.40(0.62-3.13)$ \\
\hline$<500$ & $5 I(23.1)$ & $34(66.7)$ & $17(33.3)$ & 66.7 & $1.12(0.89-1.41)$ & $1.37(0.7 \mathrm{I}-2.64)$ \\
\hline$<800$ & 79 (35.7) & $49(62.0)$ & $30(38.0)$ & 62.0 & $1.02(0.82-1.27)$ & $1.06(0.60-1.87)$ \\
\hline$<1,000$ & 91 (4I.2) & $52(57.1)$ & 39 (42.9) & 57.1 & $0.90(0.72-1.12)$ & $0.76(0.44-|.3|)$ \\
\hline$<\mathrm{I}, 300$ & $106(48.0)$ & $60(56.6)$ & $46(43.4)$ & 56.6 & $0.87(0.70-1.07)$ & $0.70(0.40-1.20)$ \\
\hline$<1,500$ & $123(55.7)$ & 71 (57.7) & $52(42.3)$ & 57.7 & $0.88(0.72-1.09)$ & $0.73(0.42-1.26)$ \\
\hline Total & $221(100.0)$ & $135(61.9)$ & $86(38.9)$ & 61.9 & & \\
\hline \multicolumn{7}{|c|}{ Patients with PSA between } \\
\hline \multicolumn{7}{|c|}{2.5 and $10.0 \mathrm{ng} / \mathrm{mL}$} \\
\hline$<200$ & $15(9.4)$ & $9(60.0)$ & $6(40.0)$ & 60.0 & $1.08(0.70-1.67)$ & $1.20(0.4 \mathrm{I}-3.54)$ \\
\hline$<300$ & $26(16.4)$ & $17(65.4)$ & $9(34.6)$ & 65.4 & $1.21(0.88-1.66)$ & $1.60(0.67-3.84)$ \\
\hline$<500$ & $39(24.5)$ & $24(6 \mid .5)$ & $15(38.5)$ & 61.5 & $1.14(0.84-1.53)$ & $1.35(0.65-2.83)$ \\
\hline$<800$ & $58(36.5)$ & $32(55.2)$ & $26(44.8)$ & 55.2 & $0.98(0.73-1.30)$ & $0.95(0.50-1.82)$ \\
\hline$<1,000$ & $66(41.5)$ & $34(5 \mid .5)$ & $32(48.5)$ & 51.5 & $0.87(0.65-1.16)$ & $0.73(0.38-1.39)$ \\
\hline$<1,300$ & $76(47.8)$ & $40(52.6)$ & $36(47.4)$ & 52.6 & $0.89(0.67-1.18)$ & $0.77(0.4 \mathrm{I}-\mathrm{I} .44)$ \\
\hline$<1,500$ & $86(54.1)$ & $46(53.5)$ & $40(46.5)$ & 53.5 & $0.91(0.69-1.20)$ & $0.80(0.43-|.5|)$ \\
\hline Total & $159(100.0)$ & $89(56.0)$ & $70(44.0)$ & 56.0 & & \\
\hline
\end{tabular}

Abbreviations: NKA, natural killer cell activity; PSA, prostate-specific antigen.

NKp46, which are activating receptors involved in the recognition of $\mathrm{PCa}$ by NK cells, are significant predictive markers for longer OS and TCR. Collectively, higher NKA provided favorable clinical outcomes that could be used as a potential new therapy in CRPC patients.

However, in contrast to previous studies, we observed that NKA measured in the peripheral blood was not significantly associated with detection of $\mathrm{PCa}$ and Gleason grade. There are several possible explanations for this discrepancy. First, among the 135 patients with PCa, the PSA was less than $20 \mathrm{ng} / \mathrm{mL}$ in $114(84.4 \%)$ patients, and biopsy Gleason grade 7 or less was identified in $92(68.1 \%)$ patients, indicating that most patients with $\mathrm{PCa}$ are not high-risk. In addition, when confined to patients with PSA between 2.5 and $10.0 \mathrm{ng} / \mathrm{mL}, 80.9 \%(72 / 89)$ of patients had Gleason grade 7 or less. Early pilot studies demonstrated that NKA was significantly lower in patients with advanced $\mathrm{PCa}$, but not different in localized PCa. ${ }^{19,27}$ In addition, Pasero et $\mathrm{al}^{28}$ found that prostatic tissues are not properly infiltrated by NK cells and described a low frequency of NK cells in both normal prostate tissue and PCa tissue.

Second, NK cells are generally categorized into CD16 $\mathrm{CD}^{6} 6^{\text {dim }}$ and $\mathrm{CD} 16^{-} \mathrm{CD} 56^{\text {bright }}$ subsets according to membrane densities of CD16 and CD56. ${ }^{29}$ CD56 ${ }^{\text {dim }}$ cells make up $90 \%-95 \%$ of NK cells and exert high cytotoxic potential, while CD56 $6^{\text {bright }}$ cells are considered immature but acquire greater cytolytic activity than CD56 ${ }^{\mathrm{dim}}$ cells when activated by pro-inflammatory cytokines. When examining the pattern of distribution of NK cells, CD56 $6^{\mathrm{dim}}$ cells are often dominant in the peripheral blood, while CD56 $6^{\text {bright }}$ cells are significantly enriched in tissues regardless of $\mathrm{PCa}$ invasion. Consequently, the NKA of patients with stable PCa was not significantly different from that of patients with a normal prostate.

A recent pilot study evaluated the association between NKA and PCa in 43 patients eligible for TRUS-guided prostate biopsy, measuring NKA with an in vitro diagnostic device (IVDD) using $1 \mathrm{~mL}$ of whole blood..$^{30}$ Of the total 43 patients, 21 (48.8\%) were diagnosed with $\mathrm{PCa}$ and, at a cut-off value of NKA less than $200 \mathrm{pg} / \mathrm{mL}$, IVDD-measured NKA provided a sensitivity of $57 \%$, specificity of $91 \%$, positive predictive value of $86 \%$, and negative predictive value of $69 \%$. Therefore, the absolute risk of having PCa with this cut-off value of IVDD-measured NKA was $86 \%$. However, these results conflict with our findings that NKA was not significantly associated with PCa detection. As the pilot study was conducted in a small number of patients with patient characteristics and PSA that were different from our study, further study in a larger population is needed to verify the implications of our results.

This study has several limitations to consider when interpreting our results. First, the measurement of NKA in the peripheral blood was only performed prior to TRUS-guided prostate biopsy and was not checked again in patients with 
PCa after definite treatment; thus, serial changes of NKA were not evaluated. Second, as our study focused on the clinical application of NKA for the detection of PCa and the prediction of Gleason grade, we did not verify our results at the cellular level in normal or cancerous prostate tissue. Third, as fluorescence-activating cell sorting analysis or K562 cytotoxicity assay could measure NKA more accurately, additional study for verification is warranted.

In conclusion, precise detection of $\mathrm{PCa}$ and prediction of Gleason grade are important to establish a treatment plan, and an additional diagnostic test is required to better determine the risk of PCa. Although NK cells play a significant role in tumor cell immunosurveillance, NKA does not appear to be very useful for detection of PCa or prediction of Gleason grade. Further large, multi-institutional studies are required to verify the role of NKA in PCa detection and Gleason grade prediction.

\section{Disclosure}

The authors report no conflicts of interest in this work.

\section{References}

1. Cuzick J, Thorat MA, Andriole G, et al. Prevention and early detection of prostate cancer. Lancet Oncol. 2014;15(11):e484-e492.

2. Schröder FH, Hugosson J, Roobol MJ, et al. Screening and prostatecancer mortality in a randomized European study. $N$ Engl J Med. 2009; 360(13):1320-1328.

3. Barry MJ, Simmons LH. Prevention of Prostate Cancer Morbidity and Mortality: Primary Prevention and Early Detection. Med Clin North Am. 2017;101(4):787-806.

4. Harvey CJ, Pilcher J, Richenberg J, Patel U, Frauscher F. Applications of transrectal ultrasound in prostate cancer. Br J Radiol. 2012; 85(Spec No 1):S3-S17.

5. Sedelaar JP, Vijverberg PL, de Reijke TM, et al. Transrectal ultrasound in the diagnosis of prostate cancer: state of the art and perspectives. Eur Urol. 2001;40(3):275-284.

6. Wolf AM, Wender RC, Etzioni RB, et al. American Cancer Society guideline for the early detection of prostate cancer: update 2010 . CA Cancer J Clin. 2010;60(2):70-98.

7. Loeb S, Bjurlin MA, Nicholson J, et al. Overdiagnosis and overtreatment of prostate cancer. Eur Urol. 2014;65(6):1046-1055.

8. Heijnsdijk EA, der Kinderen A, Wever EM, Draisma G, Roobol MJ, de Koning HJ. Overdetection, overtreatment and costs in prostatespecific antigen screening for prostate cancer. Br JCancer. 2009;101(11): 1833-1838.

9. Esserman LJ, Thompson IM, Reid B, et al. Addressing overdiagnosis and overtreatment in cancer: a prescription for change. Lancet Oncol. 2014;15(6):e234-e242.

10. Song W, Choo SH, Sung HH, et al. Incidence and management of extended-spectrum beta-lactamase and quinolone-resistant Escherichia coli infections after prostate biopsy. Urology. 2014;84(5): 1001-1007.

11. Ecke TH, Gunia S, Bartel P, Hallmann S, Koch S, Ruttloff J. Complications and risk factors of transrectal ultrasound guided needle biopsies of the prostate evaluated by questionnaire. Urol Oncol. 2008;26(5): $474-478$.
12. Gillespie JL, Arnold KE, Noble-Wang J, et al. Outbreak of Pseudomonas aeruginosa infections after transrectal ultrasound-guided prostate biopsy. Urology. 2007;69(5):912-914.

13. Vivier E, Tomasello E, Baratin M, Walzer T, Ugolini S. Functions of natural killer cells. Nat Immunol. 2008;9(5):503-510.

14. Bryceson YT, Chiang SC, Darmanin S, et al. Molecular mechanisms of natural killer cell activation. J Innate Immun. 2011;3(3):216-226.

15. Koch J, Steinle A, Watzl C, Mandelboim O. Activating natural cytotoxicity receptors of natural killer cells in cancer and infection. Trends Immunol. 2013;34(4):182-191.

16. Takahashi E, Kuranaga N, Satoh K, et al. Induction of CD16+ CD56bright NK cells with antitumour cytotoxicity not only from CD16CD56bright NK Cells but also from CD16- CD56dim NK cells. Scand J Immunol. 2007;65(2):126-138.

17. Cheng M, Zhang J, Jiang W, Chen Y, Tian Z. Natural killer cell lines in tumor immunotherapy. Front Med. 2012;6(1):56-66.

18. Imai K, Matsuyama S, Miyake S, Suga K, Nakachi K. Natural cytotoxic activity of peripheral-blood lymphocytes and cancer incidence: an 11-year follow-up study of a general population. Lancet. 2000; 356(9244):1795-1799.

19. Kastelan M, Kraljić I, Tarle M. NK cell activity in treated prostate cancer patients as a probe for circulating tumor cells: hormone regulatory effects in vivo. Prostate. 1992;21(2):111-120.

20. Lahat N, Alexander B, Levin DR, Moskovitz B. The relationship between clinical stage, natural killer activity and related immunological parameters in adenocarcinoma of the prostate. Cancer Immunol Immunother. 1989;28(3):208-212.

21. Epstein JI, Egevad L, Amin MB, et al. The 2014 International Society of Urological Pathology (ISUP) Consensus Conference on Gleason Grading of Prostatic Carcinoma: Definition of Grading Patterns and Proposal for a New Grading System. Am J Surg Pathol. 2016;40(2):244-252.

22. Ljunggren HG, Malmberg KJ. Prospects for the use of NK cells in immunotherapy of human cancer. Nat Rev Immunol. 2007;7(5):329-339.

23. Vivier E, Ugolini S, Blaise D, Chabannon C, Brossay L. Targeting natural killer cells and natural killer T cells in cancer. Nat Rev Immunol. 2012;12(4):239-252.

24. Pasero C, Gravis G, Granjeaud S, et al. Highly effective NK cells are associated with good prognosis in patients with metastatic prostate cancer. Oncotarget. 2015;6(16):14360-14373.

25. Lin SJ, Chou FJ, Li L, Lin CY, Yeh S, Chang C. Natural killer cells suppress enzalutamide resistance and cell invasion in the castration resistant prostate cancer via targeting the androgen receptor splicing variant 7 (ARv7). Cancer Lett. 2017;398:62-69.

26. Lundholm M, Schröder M, Nagaeva O, et al. Prostate tumor-derived exosomes down-regulate NKG2D expression on natural killer cells and CD8+ T cells: mechanism of immune evasion. PLoS One. 2014; 9(9):e108925.

27. Marumo K, Ikeuchi K, Baba S, Ueno M, Tazaki H. Natural killer cell activity and recycling capacity of natural killer cells in patients with carcinoma of the prostate. Keio J Med. 1989;38(1):27-35.

28. Pasero C, Gravis G, Guerin M, et al. Inherent and Tumor-Driven Immune Tolerance in the Prostate Microenvironment Impairs Natural Killer Cell Antitumor Activity. Cancer Res. 2016;76(8):2153-2165.

29. Hanna J, Bechtel P, Zhai Y, Youssef F, Mclachlan K, Mandelboim O. Novel insights on human NK cells' immunological modalities revealed by gene expression profiling. J Immunol. 2004;173(11):6547-6563.

30. Barkin J, Rodriguez-Suarez R, Betito K. Association between natural killer cell activity and prostate cancer: a pilot study. Can J Urol. 2017; 24(2):8708-8713. 
OncoTargets and Therapy

\section{Publish your work in this journal}

OncoTargets and Therapy is an international, peer-reviewed, open access journal focusing on the pathological basis of all cancers, potential targets for therapy and treatment protocols employed to improve the management of cancer patients. The journal also focuses on the impact of management programs and new therapeutic agents and protocols on

patient perspectives such as quality of life, adherence and satisfaction. The manuscript management system is completely online and includes a very quick and fair peer-review system, which is all easy to use. Visit http://www.dovepress.com/testimonials.php to read real quotes from published authors.

Submit your manuscript here: http://www.dovepress.com/oncotargets-and-therapy-journal 